\title{
Editorial
}

\section{Partnership for Health Equity}

GIOVANNI BERLINGUER, DOUGLAS BETTCHER, NICK DRAGER, TIM EVANS, GODFREY GUNATILLEKE, WENDY HARCOURT, CRAIG MURPHY, DEREK YACH AND MEG WIRTH (SID-WHO-RF EDITORIAL COMMITTEE)

The articles gathered in this last issue of Development for 1999 hopefully point the way to a new millennium of partnership and equity. This special edition is the result of partnership among the World Health Organization, the Society for International Development and the Rockefeller Foundation. These three organizations have come together because of their shared deep concern about the impact of globalization on equity and health. Globalization has ushered in a new epoch in world politics, somewhat conflictingly characterized by rapid economic transformation, new trade regimes and a growing increase in the poverty gap, along with revolutionary electronic communications and the hope held out by the new transnational social and political movements. These trends offer both possibilities and problems for public health. Concerned to discuss these trends in greater detail with a wide range of organizations involved in public health - government, policy makers, civil society groups, industry, community health, medical and research institutions and networks - the three organizations called a meeting to debate the 'responses to globalization: rethinking equity and health'.

Participants were selected from among the associates and networks of the three organizations as well as from a call for articles that was put out on the World Wide Web. This selection process leads to the invitation of a unique set of people coming from different cultures, expertise and knowledge, an age range from mid 20s to late 70s, a balance of gender, South and North representation, activism and research experience, but all holding in common a commitment to greater equity in health.

It was in many ways also a new type of meeting, in particular for WHO. As a sign of WHO's new direction with the leadership of Dr Gro Harlem Brundtland, the meeting was held in the WHO Executive Board Room, indicating that 
partnerships with NGOs are being taken very seriously. Here participants thrashed out the important concerns for equity and health, beginning with the impact of global forces on the health of local communities and leading to global strategies such as fighting for tobacco control and monitoring of the TRIPS agreements on the health of the poor. The meeting was able to shake the prescribed boxes in which people tend to discuss public health in order to build a strategic and holistic view of global health. As people from different backgrounds and interests listened to others' views and experiences, the impact of globalization on public health in all its different facets emerged. The focus was not on new medicines or new techniques but rather on the quest for information, innovation and data on how to:

- have a participatory, not top down, 'medical' model of public health;

- link the environmental, social, political and cultural in decisions around public health and disease prevention;

- build on successful community groups' responses to globalization, moving from local needs to global campaigns;

- bring in a gender and racially comprehensive approach to public health approaches; and

- move from research to innovative policy and practice.

As the conference statement printed in full in this journal indicates, the participants thoroughly politicized public health. And what was perhaps most exciting was that it was with the full endorsement and support of WHO and with the avid interest of researchers from leading medical establishments in the North and South. The civil society groups working on abortion and reproductive rights, poverty, HIV-AIDS, consumption, TRIPS, drug control, labour health and regulation, arms and peace found empathetic allies among WHO and government policy makers, medical doctors and researchers. The diversity of people and issues discussed brought out fully what a holistic agenda for public health should look like: a wide ranging agenda that takes up issues of governance and partnerships among industry, medical institutions, government and civil society; expands public health to include analysis and action on social determinants of health and global forces; meets information needs of both North and South; and builds platforms that promote advocacy, vigilance and control of public health dangers. Equity, access and transparency were underlined as the key ingredients to providing the enabling environment and ethics that could sustain health as a human right for all people. Given the richness of the articles, it was decided by the editorial committee that all of the contributions would be published here as a resource in full support of the recommendations made by the conference participants. Regrettably, this has meant that all articles are considerably scaled down from the originals discussed. The full articles are available on the SID Web Site (www.sidint.org) and we invite readers of Development to take the time to look at the complete versions. Plans are also underway to promote, sustain and develop the partnership and associated networks at the local and global levels.

The articles as they are published here divert from the normal Development sections in order to follow the structure of the conference. The journal therefore starts with a conceptual overview of globalization and public health, then takes up four cross cutting themes: governance issues; negotiating new health systems among market, state and civil society actors; the challenges of poverty, health and sustainable development, particularly communicable diseases and threats to global safety; TRIPS, pharmaceuticals, and the new international division of labour. The final section is devoted to case studies that qualify the impact of globalization on different communities.

We hope the enthusiasm and the sense of strength and togetherness all the participants felt by the end of the three days in Geneva is conveyed in these pages. We invite those who would like to participate in this partnership for health and equity to make full use of the authors' details given in the Who's Who section, as well as contacting SID directly. We look forward to continuing the partnership on all fronts. 